\title{
Erratum to: Ruin Porn and the Obsession with Decay
}

\author{
Siobhan Lyons
}

\section{Erratum to:}

S. Lyons (ed.), Ruin Porn and the Obsession with Decay, https://doi.org/10.1007/978-3-319-93390-0

In the original version of the book, the following corrections have to be incorporated:

1. Grammatical error in the opening quote of the chapter "Introduction: Ruin Porn, Capitalism, and the Anthropocene" has to be corrected.

2. Figure caption of Fig. 6.2 has to be updated.

3. Biography of Chapter 5 author "Susan A. Crane" has to be updated with the new content in frontmatter.

The erratum book has been updated with the changes.

The updated online version of the book can be found at https://doi.org/10.1007/978-3-319-93390-0

https://doi.org/10.1007/978-3-319-93390-0_1

https://doi.org/10.1007/978-3-319-93390-0_6

(C) The Author(s) 2018 https://doi.org/10.1007/978-3-319-93390-0_13 